DOI 10.37882/2500-3682.2021.05.13

\title{
ЭМОЦИОНАЛЬНЫЙ ИНТЕЛЛЕКТ: СУЩНОСТЬ И МЕСТО В СТРУКТУРЕ ЛИЧНОСТИ
}

\section{EMOTIONAL INTELLIGENCE, ITS ESSENCE AND ITS PLACE IN THE STRUCTURE OF PERSONALITY}

N. Zorina

Summary: The relevance of the topic of emotional intelligence is associated with two groups of factors. The first group of factors is the actuality of the topic for the person. The second group is the lack of a unified approach to understanding emotional intelligence, as well as its place in the structure of personality in the topic of emotional intelligence. In the article, the author examines various approaches to understanding emotional intelligence, separates social intelligence from emotional intelligence. In the structure of personality, the author distinguishes motivational, social, emotional-volitional, cognitive (intellectual) spheres of personality.

Keywords: emotional intelligence, social intelligence, personality, cognitive sphere, emotional sphere.

\author{
Зорина Наталья Николаевна \\ Соискатель, Институт психологии творчества \\ natanzorina@mail.ru
}

Аннотация: Автор полагает, что актуальность темы эмоционального интеллекта связана с двумя группами факторов: первая группа - актуальность темы для самой личности, вторая группа - отсутствие в теме единого подхода к пониманию эмоционального интеллекта и его места в структуре личности. В статье автор рассматривает различные подходы к пониманию эмоционального интеллекта, отделяет социальный интеллект от эмоционального. Говоря о структуре личности, автор выделяет мотивационную, социальную, эмоционально-волевую, когнитивную (интеллектуальную, познавательную) сферы личности.

Ключевые слова: эмоциональный интеллект, социальный интеллект, личность, когнитивная сфера, эмоциональная сфера.

целостной концепции эмоционального интеллекта" [10]. Автор отмечает, что не раскрытость закономерностей, условий и факторов формирования эмоционального интеллекта является причиной несформированности единой концепции эмоционального интеллекта. Е.Ю. Пономарева пишет о необходимости системного анализа теоретико-методологических основ концепции эмоционального интеллекта, а также выделения тех внутренних и внешних условий становления личности, которые влияют на развитие эмоционального интеллекта.

И.Н. Андреева систематизирует представления об эмоциональном интеллекте, опираясь на материал определений эмоционального интеллекта, существующий в научном поле. Она отмечает, что "общими для большинства трактовок являются представления о том, что индивиды с высоким уровнем развития ЭИ обладают выраженными способностями к пониманию эмоций (собственных и других людей), их выражению и управлению ими, что обусловливает более высокую адаптивность и эффективность в общении и деятельности" [2, с.105]. Особенностью зарубежных определений является то, что их можно разделить на три условные группы. Авторы определений первой группы понимают эмоциональный интеллект как "способность" (ability), авторы определений второй группы понимают эмоциональный интеллект как "умственные способности и потенциал" (capacity), а авторы определений третьей группы понимают его как “компетенцию”, "умение” (competence). “От- 
личия между ключевыми терминами указывают на различную расстановку акцентов - ЭИ рассматривается как врожденные возможности, приобретенные компоненты способностей, когнитивные компетенции в области эмоций" [2, с.105].

Размышляя над характером расстановки акцентов в определениях эмоционального интеллекта, также отметим, что авторы первой группы (эмоциональный интеллект как ability) говорят об эмоциональном интеллекте как некотором "врожденном явлении", врожденной способности, на наличие или отсутствие которой личность, вероятно, повлиять не в состоянии. Авторы определений второй группы (эмоциональный интеллект как capacity) близки по своему пониманию эмоционального интеллекта к авторам определений первой группы, однако, настаивают на принципиальной возможности приобретения и развития эмоционального интеллекта как способности в значении "сарасіty" (что, наряду со значением способности, имеет значение возможности, мощности, потенциала). Мы видим, что определения первой группы имеют условную временную направленность "в прошлое" (врожденные способности, которые были с нами с детства, они не зависят от нас и мы их не выбирали). В то же время, определения второй группы, несмотря на схожее значение, имеют условную направленность в "в будущее": эмоциональный интеллект как способность приобретается и развивается, заключает в себе определенный потенциал, требующий раскрытия. Наконец, определения третьей группы, где эмоциональный интеллект понимается как competence (компетенция) отстоят от определений первой и второй группы. Так, вектор направленности эмоционального интеллекта как компетенции - будущее (этим оно родственно определениям второй группы), но, в отличие от определений первой и второй группы, здесь эмоциональный интеллект понимается как приобретенный навык, не имеющий никакого “природного” (врожденного) фундамента.

Интересно, что некоторые отечественные теоретики и практики (в частности, А.Г. Шмелев, автор теста-опросника эмоционального интеллекта [11], научный руководитель HR-лаборатории, созданной на базе факультета психологии МГУ) разделяют эмоциональный интеллект и эмоциональную компетентность. Нам видится важным, что к эмоциональному интеллекту автор относит способности и личностные свойства (то есть, качества, "направленные в прошлое", в известной степени "природные" или приобретенные в раннем детстве), а к эмоциональной компетентности - уровень развитости тех или иных компонентов эмоционального интеллекта, а также уровень развитости эмоционального интеллекта в целом (вектор, направленный в будущее, “приобретенные качества").

Нам импонирует подход А.Г. Шмелева, разрешаю- щий спор о том, является ли эмоциональный интеллект "врожденным" (вариант - сформированным в раннем детстве) или "приобретенным" в более взрослом возрасте. Действительно, эмоциональный интеллект как способность приобретается личностью в раннем детстве (в зависимости от типа воспитания, характера ее социального окружения, тех или иных событий, происходящих с ней), а эмоциональная компетентность представляет собой не только уровень развития эмоционального интеллекта, но и (развитую во взрослом возрасте) способность целенаправленно управлять своими эмоциями (а также целенаправленно влиять на эмоции других людей). Такое понимание соотносится со знаменитым определением эмоциональной компетентности, данной Д. Гоулманом [5, с.153]: «эмоциональная компетентность - это способность осознавать и признавать собственные чувства, а также чувства других, для самомотивации, для управления своими эмоциями внутри себя и в отношениях с другими».

Из приведенного выше определения Д. Гоулмана очевидно, что эмоциональная компетентность подразделяется на личную (личностную) и социальную. Личная эмоциональная компетентность (в управленческом аспекте) заключается в способности распознавать собственные эмоции и целенаправленно управлять ими, а социальная эмоциональная компетентность - в том, чтобы распознавать эмоции других людей, управлять ими, а также целенаправленно влиять на отношения с другими людьми.

Личностная эмоциональная компетентность включает в себя, по нашему мнению, такие элементы: способность наблюдать за собственными эмоциями, осознание самого себя и своих эмоций, способность называть и различать свои эмоции (распознавание эмоций), способность управлять своими эмоциями, личностная заинтересованность, сочувствие себе. Социальная эмоциональная компетентность включает в себя такие навыки, как: эмпатия (и сочувствие другим людям), способность распознавать эмоции других людей, способность целенаправленно влиять на эмоции других людей, установление социального контакта, наблюдение за языком тела других людей, навыки активного слушания, навыки убеждения.

Отметим, что социальную эмоциональную компетентность не стоит путать с социальным интеллектом (расписать подробнее). Понятие социальной эмоциональной компетентности является, фактически, одним из элементов эмоционального интеллекта (навыковым, компетентностным элементом). Социальный интеллект, в свою очередь, - совокупность способностей и навыков, отвечающих за (влияющих на) успешность социального взаимодействия. Чтобы разграничить эмоциональный и социальный интеллекты, приведем существующие точки 
зрения на соотношение этих понятий:

1. эмоциональный интеллект - подструктура социального интеллекта (в рамках теории множественного интеллекта, Д. Майер, П. Сэловей, Д. Карузо);

2. эмоциональный интеллект включает в себя социальный, поскольку является более широким понятием и явлением (социальный интеллект - один из аспектов эмоционального, согласно Д. Гоулману);

3. эмоциональный интеллект - феномен, тождественный социальному интеллекту;

4. эмоциональный и социальный интеллекты - различные, но частично пересекающиеся феномены;

5. эмоциональный и социальный интеллекты - самостоятельные феномены, включенные вместе в концептуальное поле личностного интеллекта.

Также эмоциональный интеллект рассматривают как подструктуру кристаллического или часть межличностного интеллекта.

Точки зрения на соотношение социального и эмоционального интеллектов сегодня не являются достаточно обоснованными и развитыми. Так, например, попытки понимания эмоционального интеллекта как феномена, тождественного социальному интеллекту, - обречены на неуспех в силу того факта, что эмоциональный интеллект не описывает и не включает в себя всех значимых элементов социальной адаптации личности. Кроме того, концепции, описывающие социальный интеллект, влияющий на успешность социального взаимодействия, могут не включать в себя эмоциональной составляющей (влияние эмоций на успешность социального взаимодействия, эмоциональный фон успешного социального взаимодействия и т.д.). В отдельных концепциях, социальная успешность человека может рассматриваться вообще в отрыве от эмоций и эмоциональной сферы человека (так, например, изучение феномена власти может не включать в себя изучение эмоций и эмоциональной сферы).

Феноменом, связывающим эмоциональный интеллект с социальным интеллектом, можно назвать коммуникацию (общение). При этом, С.П. Деревянко [6] отмечает, что общение - категория, объединяющая социальный и эмоциональный интеллекты, в то время как разъединяющей категорией можно считать направленность общения. Коммуникативный потенциал эмоционального интеллекта нацелен на осмысление эмоциональной составляющей межличностного общения (собственных эмоций, эмоций собеседника), в то время как потенциал социального интеллекта ориентирован на успешность межличностного взаимодействия, в зависимости от целей участников этого взаимодействия.

Говоря о различиях эмоционального и социального интеллекта, отметим, что коммуникация для первого является стимулом, отправной точкой, в то время как для второго коммуникация является целью (целевым предназначением, финальной точкой). Думается, что в данном случае коммуникацию также следует разделять на эмоциональную и социальную. В широком смысле, любая коммуникация - социальная, однако, под собственно социальной коммуникацией мы имеем в виду функциональное общение, а под эмоциональной коммуникацией - эмоциональное, близкое общение, наполненное переживаниями, смыслами и т.д.

И эмоциональный, и социальный интеллект относят к "горячим видам интеллекта" [2], поскольку они имеют дело с эмоциональной, личностной, социальной информацией. Тем не менее, несмотря на близость, эти понятия описывают два самостоятельных типа интеллекта.

Рассуждая о месте эмоционального интеллекта в структуре личности, можем заметить что социальная и эмоциональная сферы в структуре личности достаточно близко связаны. Н.А. Батурин и Л.Г. Матвеева [2] различают эмоциональный и социальный интеллекты именно по "зонам их ответственности" в структуре личности. Опираясь на их понимание, можем описать зоны ответственности социального и эмоционального интеллектов.

Так, социальный интеллект в структуре личности отвечает за: социальные отношения субъекта, его взаимодействия в малых и больших социальных группах; отношения в системе социального взаимодействия: субъект-субъектные и субъект-объектные (к последним можно отнести управленческие взаимодействия); уровень развития понимания межличностных отношений и социальных отношений вообще (природы социальных отношений, отношений в социальных группах и т.д.); понимание причин поведения социальных субъектов и умение управлять их поведением.

Эмоциональный интеллект в структуре личности, в свою очередь, отвечает за: все, что относится к эмоциональной сфере (собственные эмоции, переживания и чувства, а также эмоции, переживания и чувства других людей); эмоциональный уровень межличностного взаимодействия; уровень познания эмоциональных процессов, чувств, побуждений, переживаний, поведения, вызванного эмоциями.

Говоря о месте эмоционального интеллекта в структуре личности, заметим, что концепций структуры личности также много; так, можно выделить структуры личности по 3. Фрейду, К.-Г. Юнгу, Р. Кеттеллу, А.Н. Леонтьеву, К.К. Платонову, С.Л. Рубинштейну и т.д. Масштаб данной статьи не позволяет рассмотреть эмоциональный интеллект в контекстах всех приведенных выше структур личности. Поэтому, в стремлении определить структуру личности в ее соотношении с эмоциональным интеллек- 
том, будем отталкиваться от понимания самого эмоционального интеллекта.

Так, мы можем рассматривать эмоциональный интеллект в структуре личности как врожденную (приобретенную в раннем детстве) характеристику личности, а также - как свойство личности, развитое, преимущественно, во взрослом возрасте.

Кроме того, мы будем учитывать распространенную модель личности человека, согласно которой, структура личности представлена такими основными сферами: мотивационная, эмоционально-волевая, социальная, когнитивная (интеллектуальная, познавательная).

В современных теориях эмоционального интеллекта наблюдаются различные точки зрения по поводу его места в структуре личности. Так, Д. Майер, П. Сэловей и Д. Карузо [1] определяют эмоциональный интеллект (как элемент в структуре социального интеллекта) как когнитивную способность личности, которая проявляется в наблюдении за собственными и чужими эмоциями, распознавании и идентификации их и использовании эмоциональной информации для управления мышлением и поведением (действиями). Таким образом, мы можем сделать предположение, что в этом случае эмоциональный интеллект относится к познавательной сфере личности (в данном случае речь идет об эмотивном познании мира и людей, в частности - с помощью канала невербального общения).

Р. Бар-Он определял эмоциональный интеллект как совокупность «некогнитивных способностей человека, знаний, компетенций, которые дают человеку возможность справляться с различными жизненными ситуациями» (цит. по:[10,с.104]). Так, автор выделяет такие личностные характеристики, как самопознание, межличностное общение, адаптация, преобладающие в настроении оптимизм и жизнерадостность, стрессоустойчивость, контроль за эмоциями. Тем самым, Р. Бар-Он не рассматривал когнитивную составляющую эмоционального интеллекта, относя его к свойствам, качествам, характеристикам личности [12]. Иными словами, согласно Р. Бар-Ону, эмоциональный интеллект относится к некогнитивной сфере личности. Отметим, что существуют сомнения (И.Н. Андреева) в том, справедливо ли в этом случае вообще употреблять понятие “интеллект", поскольку это понятие описывает, в первую очередь, когнитивную сферу личности (возможно, тут речь может идти об "эмоциональной интуиции").

В свою очередь, Д.В. Люсин отмечает, что в эмоциональный интеллект, наряду с когнитивными способностями, необходимо включать личностные характеристики, которые влияют на уровень и индивидуальные особенности эмоционального интеллекта [8]. В качестве такой характеристики он отмечал направленность личности на эмоциональную сферу, как собственную, так и другого человека, выделяя внутриличностный и межличностный эмоциональные интеллекты. В качестве когнитивных способностей как элемента эмоционального интеллекта, Д.В. Люсин выделял: понимание своих и чужих эмоций и управление ими, определение причин появления тех или иных эмоций и контроль за внешним проявлением эмоций. На основе этого автор говорит о двойственной природе эмоционального интеллекта: единство когнитивного компонента с одной стороны и личностных характеристик - с другой [8].

О важности взаимосвязи личностных характеристик и когнитивных способностей личности в структуре эмоционального интеллекта писал Д. Гоулман, который предложил свою модель [5]. В данной модели эмоционального интеллекта Д. Гоулман выделяет пять компонентов: самоосознанность (распознавание и понимание собственных эмоций и влияние на других людей), мотивация (стремление к достижению успеха в работе), социальные навыки общения (управление взаимоотношениями, выстраивание связей и контактов с людьми), эмпатия (понимание эмоций других людей), управление собственными эмоциями (контроль над эмоциями, совершение осознанных действий) [5]. Можно сделать вывод о том, что Д. Гоулман относил эмоциональный интеллект одновременно к мотивационной, социальной, эмоционально-волевой, когнитивной (познавательной, интеллектуальной) сферам личности.

Г.М. Бреслав рассматривает эмоциональный интеллект в качестве компонента, относящегося к эмоциональной сфере личности. Автор определяет эмоциональный интеллект как эмоциональную способность личности [4]. Созвучную точку зрения имеют Э.Л. Носенко и Н.В. Коврига, относя эмоциональный интеллект к эмоциональной сфере человека. Авторы придерживаются точки зрения о том, что эмоциональный интеллект занимает положение на границе интеллектуального и эмоционального (внутреннего и внешнего). К внутренней составляющей эмоционального интеллекта авторы относят интеллектуальную, под которой подразумевают выбор формы поведения из имеющихся альтернатив, а к внешней - эмоциональную (характеристики эмоционального поведения, его содержание). Такое место эмоционального интеллекта в структуре индивидуальности дает возможность наиболее точно отражать внутреннюю и внешнюю действительность, а эмоциональный интеллект рассматривать как проявление высокого уровня отражения психического [9].

А.В. Карпов и А.С. Петровская рассматривают эмоциональный интеллект с точки зрения теории метакогнитивизма как метапроцессуальный феномен. Авторы отмечают, что познание своих и чужих эмоций индиви- 
дом относится к когнитивной способности, а регуляция собственных эмоций, контроль над своими и чужими эмоциями относится к регулятивной составляющей (соответственно, речь идет о когнитивной и эмоциональноволевой сферах личности). Таким образом, по мнению авторов, эмоциональный интеллект как метапроцессуальный феномен, является одновременно образованием и когнитивным, и регулятивным [7].

К. Петридес и Э. Фёрнхем [14] предлагают рассматривать эмоциональный интеллект как конструкт двух составляющих: как способность и как черту личности. Эмоциональный интеллект как черта личности, с точки зрения авторов, характеризуется устойчивостью поведения человека в различных ситуациях (эмоциональноволевая сфера личности). Эмоциональный интеллект как способность, в свою очередь, предполагает определенный уровень развития отдельных компонентов эмоциональной самоэффективности (подход к ЭИ как когнитивному феномену; когнитивная, интеллектуальная сфера личности).

И.Н. Андреева предлагает рассматривать эмоциональный интеллект как интегральное когнитивноличностное образование. При этом она отмечает, что основной составляющей эмоционального интеллекта является когнитивный компонент. В связи с этим, И.Н. Андреева отмечает, что «интегральный эмоциональный интеллект может рассматриваться как совокупность умственных способностей к пониманию эмоций и управлению ими, а также знаний, умений и навыков, операций и стратегий интеллектуальной деятельности, связанных с обработкой и преобразованием эмоциональной информации» [3, с.51]. Таким образом, можно указать, что И.Н. Андреева, определяя место эмоционального интеллекта в структуре личности, относит его, в первую очередь, к когнитивной (интеллектуальной) сфере.

Подводя итоги, можно сказать, что в научном поле пока нет единой теоретической и методологической базы в понимании эмоционального интеллекта, а также нет единой модели, определяющей место эмоционального интеллекта в структуре личности.

Эмоциональный интеллект в структуре личности, согласно большинству авторов, относится к когнитивной (интеллектуальной, познавательной сфере). Тем не менее, отдельные авторы из приведенных нами выше, относят эмоциональный интеллект также к социальной сфере личности (в этом смысле, определенную трудность представляет собой отделение эмоционального интеллекта от социального), к эмоционально-волевой и мотивационной сфере. Таким образом, можно заметить, что эмоциональный интеллект охватывает все сферы личности человека.

Отдельное внимание в статье уделено социальному интеллекту как понятию, которое часто смешивают с эмоциональным интеллектом. Выше мы приводим современные трактовки эмоционального и социального интеллектов, а также сферы пересечения этих трактовок. Мы полагаем, что эмоциональный и социальный интеллекты являются разными феноменами. Так, социальный интеллект "ответственен" за достижение успеха в социальных коммуникациях, а эмоциональный - за, собственно, эмоциональную составляющую социальных коммуникаций. При этом успешной, с точки зрения социального интеллекта, - будет коммуникация, в которой достигнута некоторая функциональная цель; успешной, с точки зрения эмоционального интеллекта, будет коммуникация, в ходе которой были достигнуты эмоциональное равновесие и эмоциональная удовлетворенность коммуникантов.

\section{ЛИТЕРАТУРА}

1. Андреева И.Н. Эмоциональный интеллект в структуре индивидуальности / И.Н. Андреева // Философия и социальные науки. - 2010. - № 3. - С. 8-12.

2. Андреева И.Н. Современные представления об эмоциональном интеллекте и его месте в структуре личности / И.Н. Андреева // Журнал Белорусского государственного университета. Философия. Психология. — 2017. — № 2. - С. 104-109.

3. Андреева И.Н. 0 новой теории эмоционального интеллекта / И.Н. Андреева // Вестник БГУ. - 2011. - Серия 3. - С. $48-52$.

4. Бреслав Г.М. Психология эмоций: учеб. пособие для студентов вузов, обучающихся по направлению и специальностям «Психология», «Клиническая психология» / Гершон Бреслав. - М.: Смысл : Academia, 2004. - 541с.

5. Гоулман, Д. Эмоциональный интеллект [Текст] / Дэниел Гоулман; [пер. с англ. А.П. Исаевой]. - Москва: АСТ: Астрель, 2011. - 478 с.

6. Деревянко С.П. Эмоциональный интеллект: проблемы категориальности // Психология в современном информационном пространстве : материалы Междунар. науч. конф. (Смоленск, 23-24 нояб. 2007 г.): в 2 ч. Смоленск, 2007.

7. Карпов А.В. Психология эмоционального интеллекта: теория, диагностика, практика : [монография] / А.В. Карпов, А.С. Петровская; М-во образования и науки Российской Федерации, Федеральное агентство по образованию, Ярославский гос. ун-т им. П.Г. Демидова. - Ярославль: ЯрГУ, 2008 (Ярославль: Ремдер). - 344 c.

8. Люсин Д.В. Современные представления об эмоциональном интеллекте / Д.В. Люсин // Социальный интеллект: Теория, измерение, исследования / под ред. Д.В. Люсина, Д.В. Ушакова. - М., 2004. - С. 29-36. 
9. Носенко, Е.Л. Емоційний інтелект: концептуализація феномену, основні функціі / Е.Л. Носенко, Н.В. Коврига. - Київ, 2003. - 126 с.

10. Пономарева Е.Ю. Сущностная характеристика природы эмоционального интеллекта / Е.Ю. Пономарева // Гуманитарные науки. - 2019- № 3 C. 102-106.

11. Психология общения [Текст] : энциклопедический словарь / Российской акад. образования, Психологический ин-т; под общ. ред. А.А. Бодалева. - 2-е изд., испр. и доп. - Москва : Когито-Центр, 2015. -Ч. 1. С. 108-112.

12. Bar-0n R. The Bar-On Emotional Quotient Inventory (EQ-i): Technical Manual /R. Bar-On. - Toronto: Multi-Health Systems, 1997. - 120 p.

13. Mayer J.D., Di Paolo M., Salovey P. Perceiving affective content in ambiguous visual stimuli: a component of emotional intelligence // J. Pers. Assess. 1990. Vol. 54, № 3/4.P. 772-781.

14. Petrides, K.V., Frederickson, N., Furnham, A. The role of trait emotional intelligence in academic performance and deviant behavior at school / K.V. Petrides, N. Frederickson, A. Furman // Personality and Individual Differences, 2004, 277-293.

15. Salovey P., Mayer J.D. Emotional intelligence // Imagination, Cognit. Pers. 1990. Vol. 9. P. 185-211.

(c) Зорина Наталья Николаевна (natanzorina@mail.ru).

Журнал «Современная наука: актуальные проблемы теории и практики» 